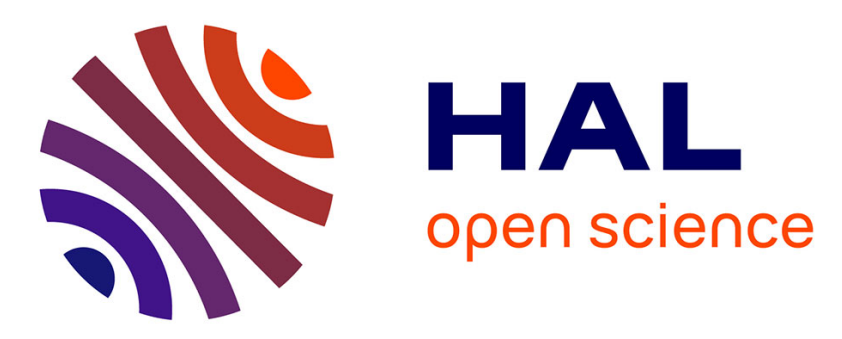

\title{
Branching of dipolar chromophores: effects on linear and nonlinear optical properties
}

Claudine Katan, Francesca Terenziani, Céline Le Droumaguet, Olivier Mongin, M.H.V. Werts, Sergei Tretiak, Mireille Blanchard-Desce

\section{To cite this version:}

Claudine Katan, Francesca Terenziani, Céline Le Droumaguet, Olivier Mongin, M.H.V. Werts, et al.. Branching of dipolar chromophores: effects on linear and nonlinear optical properties. Linear and Nonlinear Optics of Organic Materials V, Aug 2005, San Diego, United States. pp.593503, $10.1117 / 12.618464$. hal-00489937

\section{HAL Id: hal-00489937 https://hal.science/hal-00489937}

Submitted on 7 Jun 2010

HAL is a multi-disciplinary open access archive for the deposit and dissemination of scientific research documents, whether they are published or not. The documents may come from teaching and research institutions in France or abroad, or from public or private research centers.
L'archive ouverte pluridisciplinaire HAL, est destinée au dépôt et à la diffusion de documents scientifiques de niveau recherche, publiés ou non, émanant des établissements d'enseignement et de recherche français ou étrangers, des laboratoires publics ou privés. 


\title{
Branching of dipolar chromophores: effects on linear and nonlinear optical properties
}

\author{
Claudine Katan ${ }^{\mathrm{a}}$, Francesca Terenziani ${ }^{\mathrm{a}}$, Céline Le Droumaguet ${ }^{\mathrm{a}}$, Olivier Mongin ${ }^{\mathrm{a}}$, \\ Martinus H. V. Werts ${ }^{\mathrm{a}}$, Sergei Tretiak* ${ }^{\mathrm{b}}$, Mireille Blanchard-Desce ${ }^{*^{\mathrm{a}}}$ \\ ${ }^{a}$ Synthèse et ElectroSynthèse Organiques (CNRS, UMR 6510), Université de Rennes 1, Institut de \\ Chimie, Campus de Beaulieu, Bât 10A, F-35042 Rennes Cedex, France; \\ ${ }^{\mathrm{b}}$ Los Alamos National Laboratory, Theoretical Division, Los Alamos, New Mexico 87545, USA
}

\begin{abstract}
Structurally related chromophores of different symmetry (dipolar, V-shaped, octupolar) are investigated and compared for elucidation of the combined role of branching and charge symmetry on absorption, photoluminescence and twophoton absorption (TPA). Their design is based on the assembly of one, two or three $\pi$-conjugated dipolar branches on a central core. Two series of branched structures obtained from a central triphenylamine core and dipolar branches having different charge-transfer characters are investigated: photophysical properties are studied and TPA spectra are determined through two-photon excited fluorescence experiments using fs pulses in the 700-1000 nm range. Calculations based on time-dependent quantum-chemical approaches, as well as the Frenkel exciton model, complement experimental findings. Experiments and theory reveal that a multidimensional intramolecular charge transfer takes place from the central electron-donating moiety to the periphery of the branched molecules upon excitation, whereas fluorescence stems from a dipolar branch. Symmetry and inter-branch electronic coupling are found to be responsible for amplification of the TPA response of branched compounds with respect to their monomeric analogues. In particular, an enhancement is observed in regions where the TPA bands overlap, and TPA activation is obtained in spectral regions where the dipolar analogue is almost two-photon transparent. Thus, appropriate tuning of the number of branches, of the coupling between them, and modulation of intramolecular charge transfer from core to periphery open the way for substantial improvement of TPA efficiency or TPA induction in desired spectral regions.
\end{abstract}

Keywords: two-photon absorption, excitonic coupling, luminescence, multidimensional intramolecular charge transfer

\section{INTRODUCTION}

Molecular two-photon absorption (TPA) has attracted increasing interest over recent years owing to the many applications it offers. This has prompted the search for compounds displaying enhanced TPA cross-sections. Depending on the applications, two-photon chromophores have to satisfy different kinds of requirements. For instance, combination of high fluorescence quantum yield $(\Phi)$ and TPA cross-section $\left(\sigma_{2}\right)$ in the red-NIR range $(700-1200 \mathrm{~nm})$ are desirable for biological imaging. A number of factors influence the TPA magnitude, among which electronic delocalization and intramolecular charge transfer phenomena. In recent years, considerable effort has been devoted to the design and investigation of chromophores with large TPA cross-section, exploring in particular dipolar ${ }^{1-8}$ and quadrupolar, $2,4,6,8-21$ structures. Lately, attention has turned towards multipolar ${ }^{22-32}$ and branched structures such as dendrimers. $22,23,27,32-43$ Experimental investigation of the branching effect has led to various trends: cooperative enhancement, ${ }^{23,37,39,40,43}$ additive behavior ${ }^{35,36}$ or even reduction of $\mathrm{TPA}^{36}$ have been reported, depending on the molecular structures. Among the reasons that lead to these apparently conflicting findings, two can be put forward. Firstly, most of these studies were limited to single wavelength measurements ${ }^{23,24,30,34-36,39}$ which can obviously lead to discrepancies, since spectral position and shape always play an important role. Secondly, the nature of the branches (dipolar versus quadrupolar, for example) will also be of major importance as it affects interbranch coupling. Given the huge synthetic effort needed to build such structures, detailed understanding of the effect of branching of molecular entities on the linear and nonlinear optical properties is of major interest. Thus, further development of approaches for rational design of NLO assemblies is needed

* mireille.blanchard-desce@ univ-rennes1.fr; phone/fax +332232362 77; http://www.umr6510.univ-rennes1.fr/epm/ serg@cnls.lanl.gov; phone: +1 505 667-8351; fax: +1 505 665-3909; http://www.t12.lanl.gov/home/serg/homepage.html 
in order to focus the synthesis on knowledge-based materials. Among the many questions that are still debated, coherent coupling between the arms (building blocks) is of particular interest. Depending on the nature of this coupling, the ground or the excited state may be either localized or delocalized and specific optical properties may be either enhanced or suppressed. $^{44}$

The aim of this paper is to thoroughly investigate the effect of branching of dipolar chromophores on photoluminescence and TPA by combining various experimental and theoretical approaches. These include UV/VIS spectra, fluorescence, fluorescence decay and fs two-photon-excited fluorescence measurements, state of the art quantum-chemical approaches as well as simple interpretative models. The paper will focus on the branching of dipolar entities in the weak-medium interaction limit. Asymmetrically substituted stilbene chromophores bearing electron-withdrawing end-groups $\left(\mathrm{SO}_{2} \mathrm{Oct}\right.$ or $\mathrm{SO}_{2} \mathrm{CF}_{3}$, Scheme 1 and 2) have been chosen as prototypes for this class. Grafting of one, two or three branches on an electron-donating triphenylamine core leads to (multi)polar chromophores of different symmetry: dipolar, V-shaped and octupolar. The linear and nonlinear photophysical properties of the synthesized compounds are thoroughly explored through a combined analysis of experimental and theoretical results. The solvatochromic behavior of one-photon spectra, combined with excited state lifetimes, suggests an emitting excited state localized on one branch. This phenomenon of excitation localization is investigated and corroborated through quantum-chemical excited state calculations. Twophoton spectra of branched chromophores show a cooperative enhancement with respect to the dipolar analogue in the visible red region as well as in the near-infrared. These results can be qualitatively interpreted as resulting from the splitting of excited states due to the coupling between the dipolar branches (Frenkel exciton model). Time-dependentdensity functional calculations allow to reproduce and interpret all observed experimental trends. Increasing the electronacceptor strength of the end-groups leads to red-shifted one- and two-photon bands and to a tuning of the charge transfer ability, with a consequent interesting enhancement of the TPA cross-section in the red-NIR region. The reported results suggest new routes for TPA enhancement and for rational design of optimized structures for NLO.

\section{METHODOLOGY}

\subsection{Synthesis of the chromophores}

Dipolar chromophores 1a and $\mathbf{1 b}$ were prepared by a Horner-Wadworth-Emmons reaction between the monoaldehyde derived from triphenylamine and the corresponding phosphonates. Following the same way, the V-shaped chromophore 2a was obtained by using the corresponding dialdehyde ${ }^{45}$ (Scheme 1).

The trialdehyde core was prepared by a triple Vilsmeier-Haack formylation from triphenylamine. ${ }^{46}$ The octupolar fluorophore 3a was obtained by means of a triple Horner-Wadworth-Emmons condensation between this trialdehyde and the corresponding phosphonate. ${ }^{45}$ The trivinyl core was prepared by triple Wittig condensation from the trialdehyde and the octupolar chromophore $\mathbf{3 b}$ was synthesized by means of triple Heck coupling between this vinyl compound and the corresponding bromo derivative ${ }^{47}$ (Scheme 2).
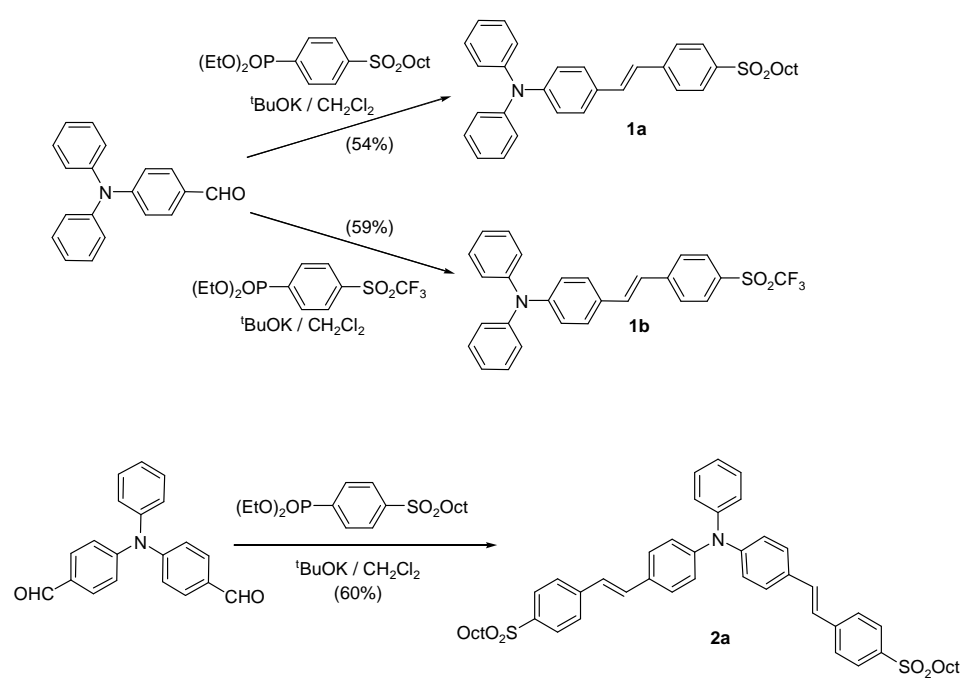

Scheme 1: Synthesis of dipolar (1a and $\mathbf{1 b}$ ) and V-shaped (2a) chromophores. 


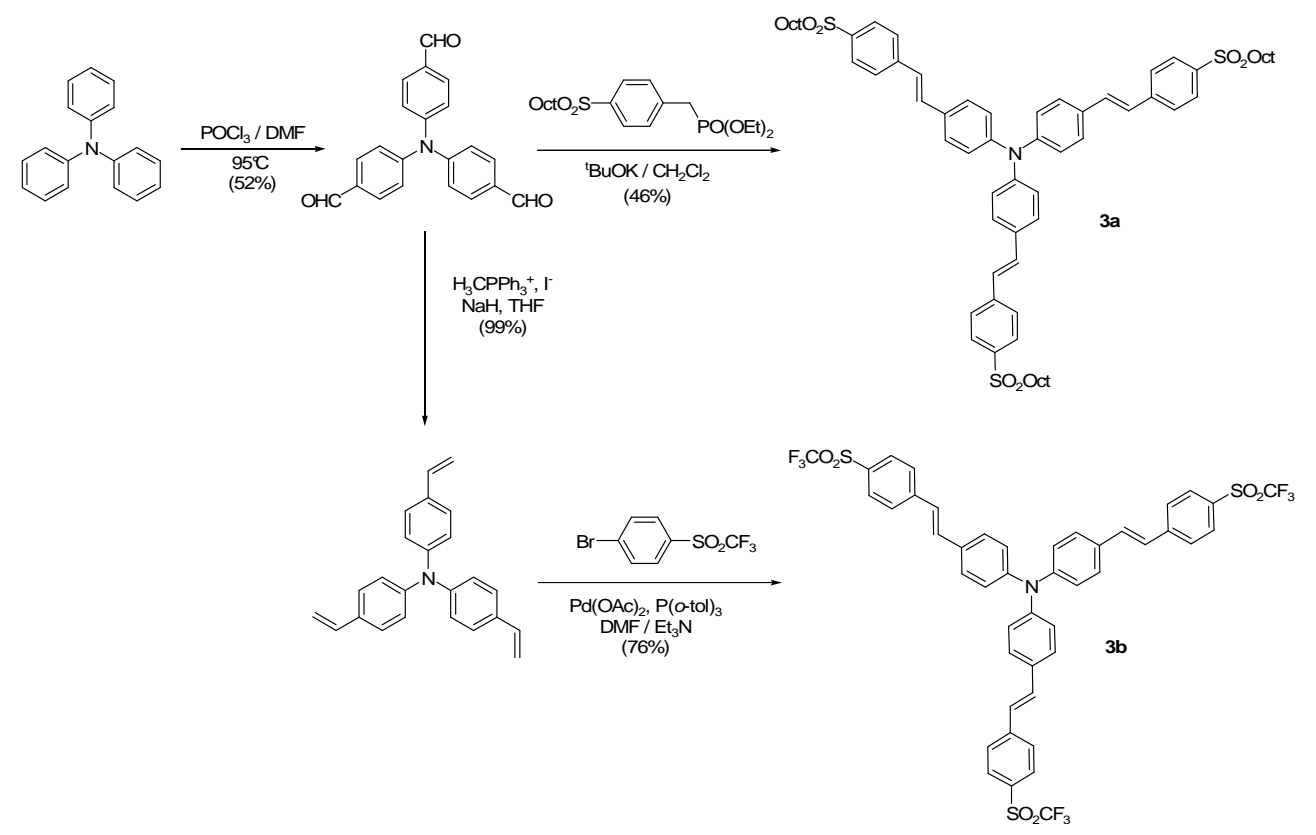

Scheme 2: Synthesis of octupolar chromophores $\mathbf{3 a}$ and $\mathbf{3 b}$.

\subsection{Photophysical methods}

UV/VIS spectra were recorded on a Jasco V-570 spectrophotometer. Steady-state and time resolved fluorescence measurements were performed at room temperature in dilute solutions $\left(c a .10^{-6} \mathrm{M}\right)$ using an Edinburgh Instruments (FLS 920) spectrometer in photon-counting mode. Emission spectra were obtained, for each compound, at $\lambda_{\mathrm{ex}}=$ $\lambda_{\max }(\mathrm{abs})$ with $\mathrm{A} \leq 0.1$ at $\lambda_{\mathrm{ex}}$ to minimize internal absorption. Fluorescence quantum yields were measured on degassed samples at room temperature; fluorescein in $0.1 \mathrm{~N} \mathrm{NaOH}$ was used as a standard (quantum yield $\Phi=0.90$ ). ${ }^{48}$ The lifetime values were obtained from the reconvolution fit analysis of the decay profiles with the F900 analysis software and the fitting results were judged by the reduced $\chi^{2}$ value.

Two-photon absorption cross-sections $\left(\sigma_{2}\right)$ were determined by the two-photon-excited fluorescence (TPEF) technique in solution (concentration $\mathrm{ca}$. $10^{-4} \mathrm{M}$ ). These measurements provide the TPEF action cross-section $\sigma_{2} \Phi$. The corresponding $\sigma_{2}$ values were derived by determining the fluorescence quantum yield $\Phi$ from standard fluorescence measurements. TPEF measurements were conducted using a mode-locked Ti:sapphire laser operating between 700 and $1000 \mathrm{~nm}$ and delivering 80 -fs pulses at $80 \mathrm{MHz}$, following the experimental protocol described in detail by Xu and Webb. ${ }^{49}$ The quadratic dependence of the fluorescence intensity on the excitation intensity was verified for each data point, indicating that the measurements were carried out in intensity regimes in which saturation or photodegradation do not occur. TPEF measurements were calibrated relative to the absolute TPEF action cross-section determined by Xu and Webb for fluorescein in water $(\mathrm{pH}=11)$ in the $690-1000 \mathrm{~nm}$ range. ${ }^{49,50}$ The experimental uncertainty does not exceed $\pm 10 \%$.

\subsection{Theoretical approaches}

Various quantum-chemical approaches have been employed to model all chromophores of interest, including their linear and non linear optical properties. For the sake of simplicity, the alkyl solubilizing chains for chromophores 1a-3a have been replaced by methyl groups. Solvation effects were neglected. Ground state optimized geometries have been obtained using the Gaussian 98 package. ${ }^{51}$ For ground state geometries, we previously found that the Hartree-Fock (HF) method is superior to the hybrid $\mathrm{B} \mathrm{LYP}^{52}$ approach by reproducing accurately bond length alternation parameter in similar conjugated systems when compared to experiment. ${ }^{45,53}$ Thus, all ground state geometries used for discussion are obtained at the HF level using the 6-31G basis set.

It is well known that time dependent (TD)-HF lacks important electronic correlations and therefore excited states are systematically and significantly blue-shifted with respect to experiments. In contrast, time-dependent density functional 
theory (TD-DFT) much better reproduces excited state properties of many systems. ${ }^{54}$ However, pure and gradientcorrected DFT functionals do not reproduce charge transfer states (HF does within a certain approximation). This can be partly cured by hybrid functionals such as B3LYP and was found to be very accurate for excited states in many molecular systems. ${ }^{54-56}$ Therefore we used TD-B3LYP/6-31G level of theory to investigate linear and nonlinear optical properties using the density matrix formalism for nonlinear optical responses as described in ref. ${ }^{57}$ This method has already demonstrated its accuracy for both linear and nonlinear spectra in different series of substituted chromophores. ${ }^{53,58,59}$ Excited state electronic structures, with 24 excited states for each molecule, were calculated with Gaussian 98. ${ }^{51}$ Vertical transition frequencies $\Omega_{g v}$, dipoles $\mu_{g v}$ and densities $\xi_{g v}$ are used to model both linear absorption and TPA spectra. ${ }^{57}$ The linear absorption at frequency $\omega$ is given by the imaginary part of

$$
\alpha(\omega)=\sum_{v} \frac{f_{g v}}{\Omega_{g v}^{2}-(\omega+i \Gamma)^{2}},
$$

where $\Gamma$ is the linewidth, and $f_{g v}$ is the oscillator strength associated with the $|g\rangle$ to $|v\rangle$ electronic transition. The TPA cross-section $\sigma_{2}(\omega)$ is related to the imaginary part of the third order polarizability $\chi(-\omega, \omega, \omega,-\omega)$ by ${ }^{53}$

$$
\sigma_{2}(\omega)=\frac{4 \pi^{2} \hbar \omega^{2}}{n^{2} c^{2}} L^{4} \operatorname{Im}\langle\gamma\rangle
$$

where $\hbar$ is Plank's constant, $c$ is the speed of light, $n$ is the refractive index of the medium (for toluene, $n=1.494$ ), $L$ is the local field factor $\left(L=\left(n^{2}+2\right) / 3\right)$, and

$$
\langle\gamma\rangle=\frac{1}{15}\left(3 \sum_{i} \gamma_{i i i i}+\sum_{j \neq i}\left(\gamma_{i i j j}+\gamma_{i j i j}+\gamma_{i j j i}\right)\right)
$$

is the orientational average of $\gamma$ following Eq. (6) in ref. $\left.{ }^{60} \chi-\omega, \omega, \omega,-\omega\right)$ has been calculated using the density matrix formalism as described in ref. ${ }^{57}$ and implemented in ref. ${ }^{53}$ All comparisons with experiment for amplitude of the responses are subject to an uncertainty in the choice of the line-broadening parameter $\Gamma$. In all calculations we used an empirical linewidth $\Gamma=0.1 \mathrm{eV}$.

To model fluorescence spectra we used the TURBOMOLE ${ }^{61}$ package to optimize molecular geometries for the lowest excited state at TD-HF/6-31G level. Thus for all subsequent analysis we will consistently use molecular geometries based on HF and TD-HF approaches and excited states calculated with TD-B3LYP method. Namely absorption and fluorescence points were treated at TD-B3LYP/6-31G//HF/6-31G and TD-B3LYP/6-31G//TD-HF/6-31G levels, respectively, in conventional quantum chemical notation "single point//optimization level". At excited state optimal geometry, transition frequencies $\Omega_{g e}^{(f)}$ and dipoles $\mu_{g e}^{(f)}$ corresponding to the vertical fluorescence process were used to calculate the radiative lifetime $\tau_{0}$ according to the Weisskopf-Wigner equation for the radiative decay rate: ${ }^{62}$

$$
\frac{1}{\tau_{0}}=\frac{1}{4 \pi \varepsilon_{0}} \frac{4 \Omega_{g e}^{(f)^{3}} \mu_{g e}^{(f)^{2}}}{3 \hbar c^{3}} L,
$$

where $\varepsilon_{0}$ is the vacuum permittivity (MKS units) and $L$ accounts for local-field effects. ${ }^{63}$

To analyze the nature of the excited states involved in the photophysical processes we used natural transition orbital analysis of the excited states ${ }^{64,65}$ based on the calculated transition densities. This analysis offers the most compact representation of a given transition density in terms of an expansion into single-particle transitions. Wavefunctions for degenerate states in the octupolar specimen are defined by implementation of Davidson diagonalization in Gaussian $98^{51}$ and differ from the "canonical" eigenfunctions $1 / \sqrt{6}\left(2 \phi_{1}-\phi_{2}-\phi_{3}\right)$ and $1 / \sqrt{2}\left(\phi_{2}-\phi_{3}\right){ }^{26}$ Figures showing molecular geometries and transition orbitals were obtained with Molekel ${ }^{66}$ and XCrySDen, ${ }^{67}$ respectively.

To connect the photophysical properties of multi-branched chromophores to those of their single-branch counterpart, we also use a Frenkel exciton model. ${ }^{68,69}$ This approach assumes an electrostatic interaction $(V)$ between monomers, which is small compared to the typical transition energy $(V<<\Omega)$. The intermolecular coupling does not necessarily have to be of dipole-dipole nature and the chromophores do not necessary have to be spatially separated (phenylacetylene dendrimers are examples of such cases ${ }^{70}$ ). As it is the case for many conjugated molecules, the lowest excited state of the monomeric constituent (1a or $\mathbf{1 b}$ ) with frequency $\Omega_{g e}$ (which is the origin of excitonic manifold in multi-branched chromophores) is expected to be responsible for the dominant contributions in the spectra. In particular, the Frenkel exciton Hamiltonian for two- and three-branched chromophores, for the lowest excitonic manifold is given by: 


$$
H=\Omega_{g e} \sum_{i}^{2 o r 3} B_{i}^{+} B_{i}+V \sum_{i, j \neq i}^{2 o r 3} B_{j}^{+} B_{i}
$$

where $B_{i}^{+}\left(B_{i}\right)$ are the excitonic creation (annihilation) operators on branch $i$. After diagonalization of Hamiltonian (5), ${ }^{26}$ the resulting splittings in energies of the excitonic states are cartooned in Scheme 3, where $|\mathbf{g}\rangle$ denotes the ground state, $|\mathbf{e}\rangle,|\mathbf{e}\rangle$ and $\left|\mathbf{e}^{\prime}\right\rangle$ the excited states. The V-shaped character of $\mathbf{2 a}$ is responsible for the non-vanishing one-photon oscillator strength of the symmetric (higher energy) state $\mathbf{2}\left|\mathbf{e}^{\prime}\right\rangle$, even if the $\mathbf{2}|\mathbf{e}\rangle$ is the most one-photon allowed state. If $C_{3}$ symmetry is assumed for the 3-branched systems, a two-fold degenerate first excited state (|e and $\left.\mid \mathbf{e} '>\right)$ is obtained, which is both one- and two-photon allowed, while excited state $\left|\mathbf{e}^{\prime \prime}\right\rangle$ is only two-photon allowed.

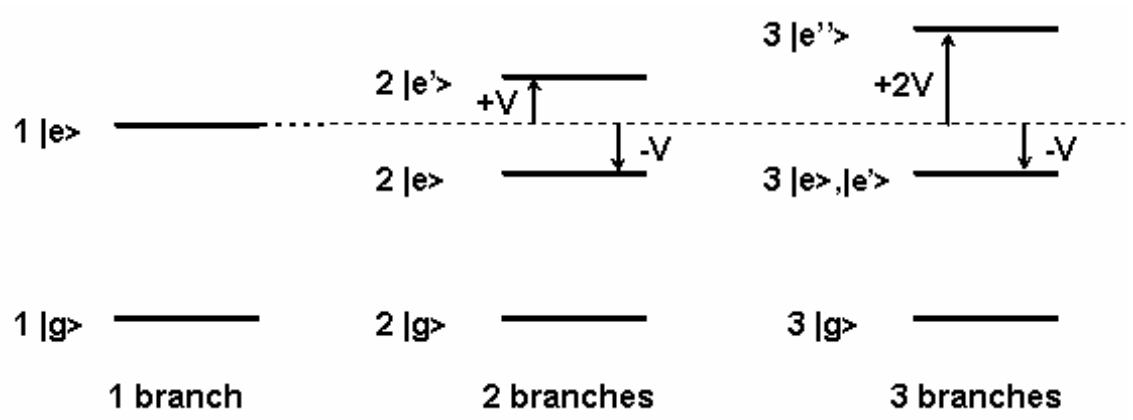

Scheme 3: Schematic electronic level diagram of the single branch (left) and of the molecular systems built from gathering 2 (middle) or 3 (right) such branches within the excitonic model. $|\mathbf{g}\rangle$ denotes the ground state, $|\mathbf{e}\rangle,|\mathbf{e}\rangle$ and $\mid \mathbf{e}$ '” the excited states and $V$ the coupling between adjacent branches. $C_{3}$ symmetry has been assumed for the 3-branched system leading to a two-fold degenerate first excited state $\left(|\mathbf{e}\rangle\right.$ and $\left.\left|\mathbf{e}^{\prime}\right\rangle\right)$.

\section{RESULTS AND DISCUSSION}

\subsection{Molecular geometry}

Ab-initio calculations indicate that in all investigated chromophores the triphenylamine moiety adopts a propeller-shaped structure, the phenyl rings being twisted (between $35^{\circ}$ and $51^{\circ}$ ) with respect to the trigonal planar nitrogen (Figure 1 ). Triphenylamine allows for either left or right handed skewness of the propeller core, with corresponding acceptor endgroups either approximately coplanar or perpendicular to the molecular mean plane. Both geometries lead to identical total energies and small differences in the vector components of the dipole moment. No significant differences are found for the one and two-photon absorption spectra. The two phenyl rings of the conjugated stilbenyl branches are substantially twisted $\left(\sim 40^{\circ}\right)$. Overall, branches in multipolar systems have ground state geometries similar to the geometry of the parent dipolar molecule. Ground state optimized geometries are in good agreement with crystallographic data. $^{71}$

Excited state geometries are different. First of all, the structure of the stilbenyl branch in $\mathbf{1 a}$ and $\mathbf{1 b}$ becomes planar with vanishing bond-length alternation parameter (Figure 1). This is a generic phenomenon observed in many extended molecular systems such as conjugated polymers. ${ }^{72,73}$ The structures of multi-branched chromophores do not retain their symmetries: roughly, one branch adopts geometry almost coincident to the excited state geometry of the parent molecule (1a or 1b), whereas the other branch(es) behave differently: in the case of $\mathbf{2 a}$ and $\mathbf{3 a}$ they remain in their ground state geometry, ${ }^{45}$ while for $\mathbf{3 b}$ they reduce the twist between the two rings of the stilbenyl motif up to $\sim 10^{\circ}$ (Figure 1 ). The symmetry breaking observed in the relaxed excited states of multibranched chromophores is an indication that fluorescence originates from an excitation localized on a single branch rather than from a fully delocalized state. 


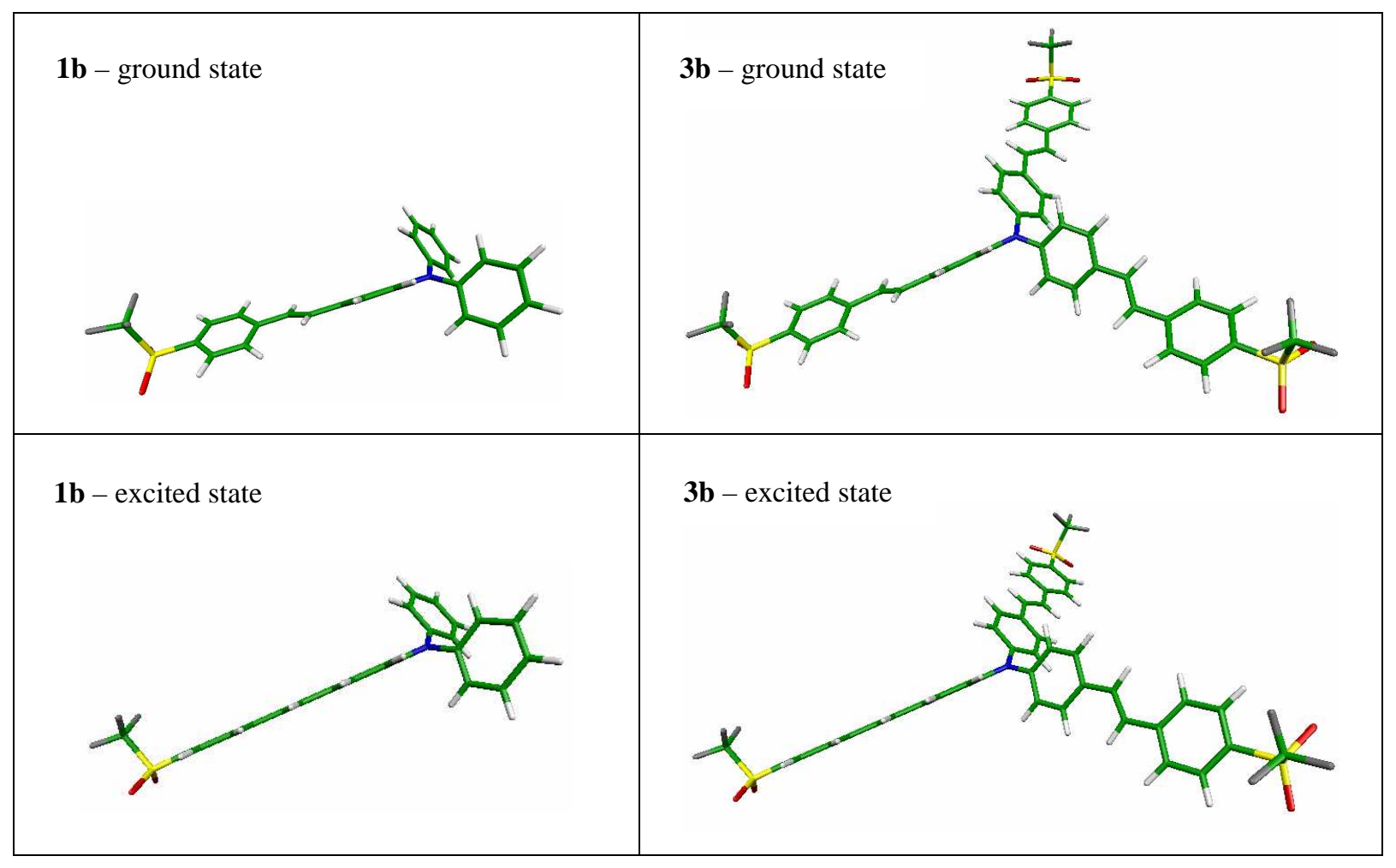

Figure 1: Optimized geometries of chromophore $\mathbf{1 b}$ (left) and chromophore $\mathbf{3 b}$ (right) for ground- (top) and excited-state (bottom).

\subsection{Photophysical properties}

The (experimental and theoretical) photophysical characteristics of the investigated chromophores are summarized in Table 1. The agreement between experiment and theory is good. By increasing the size of the basis, this agreement can be further improved, ${ }^{45}$ but we kept 6-31G level of theory throughout the paper for consistency (a higher level of theory for excited state calculations of $\mathbf{3 a}$ and $\mathbf{3 b}$ is over-demanding). The chromophores show an intense absorption band in the near UV-blue visible region (Figure 2). Gathering dipolar units (chromophores 1a and 1b) via a common electrondonating nitrogen within either V-shaped (two-branched compound 2a) or trigonal (three-branched compounds 3a and 3b) branched molecules leads to a slight red-shift of the absorption bands (Figure 2). This is indicative of sizeable coupling between the dipolar branches that can be described using the excitonic model (Scheme 3 ).

The molar extinction coefficients were found to increase almost linearly with the number of branches, indicative of a nearly additive behavior (Table 1). The first excited state corresponds to electron transfer from the highest occupied transition orbital $^{64}$ (HOTO) to the lowest unoccupied transition orbital (LUTO) (and LUTO+1 for compounds 3a and 3b) and is common to all investigated molecules (Figure 3 and 4). The two-branched V-shaped chromophore 2a is found to display the largest half-bandwidth. Calculations and comparison between absorption and emission spectra confirm that this broad and asymmetric absorption band results from the overlap of two close low-lying excited states. ${ }^{45}$ The second excited state corresponds to electron transfer from HOTO to LUTO+1. We observe that the splitting is symmetric with respect to the first excited state of the monomer as predicted by the excitonic model (Scheme 3). From both experimental $^{45}$ and theoretical results (Table 2), the coupling constant $V$ is estimated to be $\sim 0.14 \mathrm{eV}$. In contrast, the third excited state of the three-branched chromophores, for which the two first excited states are degenerate, has vanishing oscillator strength. Thus, the first absorption band of chromophores $\mathbf{3 a}$ and $\mathbf{3 b}$ does not show any spectral broadening. The energy difference between the degenerate first two excited states of octupolar compounds and the first excited state of the corresponding monomer leads to a coupling constant $V$ of again $\sim 0.14 \mathrm{eV}$ for $3 \mathbf{a}$ and of $\sim 0.10 \mathrm{eV}$ for 3b. These values are in good agreement with those deduced from TD-B3LYP calculations. The position of the third excited state (e') of chromophores $\mathbf{3 a}$ and $\mathbf{3 b}$ - which is one-photon forbidden but two-photon allowed - is thus predicted to show up at $0.42 \mathrm{eV}$ and $0.30 \mathrm{eV}$, respectively, (Scheme 3) above the two first excited states (thus at about 
720 and $780 \mathrm{~nm}$ for $\mathbf{3 a}$ and $\mathbf{3 b}$, respectively, for two-photon absorption). Actually, calculations for $\mathbf{3 b}$ predict that e'" is not symmetrically displaced with respect to the monomer, but slightly blue-shifted.

The photoluminescence characteristics were found to depend on the dimensionality of the molecule. Even if chromophores have similar emission spectra by varying the number of branches, two- and three-branched chromophores exhibit higher fluorescence quantum yields than their one-dimensional dipolar analogues (Table 1). Interestingly, we also find that the derived radiative lifetimes $\left(\tau_{0}=\tau / \Phi\right)$ are almost constant all along the series (Table 1). This confirms that emission does not stem from a delocalized excited state in branched molecules, otherwise a decrease of the radiative lifetime would be expected as a result of the linear increase in the molar extinction coefficients with the number of branches (see Eq. (4)). ${ }^{74}$ The theoretical computation of radiative lifetimes (Table 1) underestimates experimental values but correctly reproduces experimental trends.

Table 1: Photophysical data of the investigated chromophores (in toluene).

\begin{tabular}{|c|c|c|c|c|c|c|c|c|c|c|c|}
\hline & $\begin{array}{l}\lambda_{\mathrm{abs}}^{\exp a} \\
(\mathrm{~nm})\end{array}$ & $\begin{array}{l}\lambda_{\mathrm{abs}}^{\mathrm{calc} b} \\
(\mathrm{~nm})\end{array}$ & $\begin{array}{c}\varepsilon_{\max }{ }^{c} \\
\left(\mathrm{~cm}^{-1} \mathrm{~mol}^{-1} \mathrm{~L}\right)\end{array}$ & $\begin{array}{l}\mu_{g e}{ }^{d} \\
\text { (D) }\end{array}$ & $\begin{array}{l}\lambda_{\mathrm{em}}^{\exp e} \\
(\mathrm{~nm})\end{array}$ & $\begin{array}{l}\lambda_{\mathrm{em}}^{\mathrm{calc}_{f}} \\
(\mathrm{~nm})\end{array}$ & $\begin{array}{l}\text { Stokes } \\
\text { Shift } \\
\left(\mathrm{cm}^{-1}\right)\end{array}$ & $\Phi^{g}$ & $\begin{array}{c}\tau^{h} \\
(\mathrm{~ns})\end{array}$ & $\begin{array}{l}\tau_{0}^{\exp i} \\
(\mathrm{~ns})\end{array}$ & $\begin{array}{l}\tau_{0}^{\mathrm{calc} l} \\
(\mathrm{~ns})\end{array}$ \\
\hline $1 a$ & 392 & 408 & $2.9 \cdot 10^{4}$ & 6.2 & 456 & 454 & 3580 & 0.58 & 1.4 & 2.5 & 1.55 \\
\hline $2 a$ & 409 & 429 & $5.0 \cdot 10^{4}$ & 8.9 & 459 & 480 & 2660 & 0.74 & 1.6 & 2.1 & 1.51 \\
\hline $3 a$ & 410 & 428 & $7.9 \cdot 10^{4}$ & 10.4 & 463 & 486 & 2790 & 0.72 & 1.7 & 2.3 & 1.59 \\
\hline $1 \mathrm{~b}$ & 415 & 437 & $2.4 \cdot 10^{4}$ & 6.3 & 508 & 475 & 4410 & 0.47 & 1.5 & 3.2 & 1.65 \\
\hline $3 b$ & 430 & 450 & $8.1 \cdot 10^{4}$ & 11.4 & 494 & 508 & 3010 & 0.71 & 1.8 & 2.6 & 1.76 \\
\hline
\end{tabular}

${ }^{a}$ Experimental one-photon absorption maximum.

${ }^{b}$ Calculated one-photon vertical absorption maximum at TD-B3LYP/6-31G//HF/6-31G level.

${ }^{c}$ Experimental molar extinction coefficient on the first maximum of the absorption band.

${ }^{d}$ Experimental transition dipole moment.

${ }^{e}$ Experimental one-photon emission maximum.

${ }^{f}$ Calculated one-photon vertical emission maximum at TD-B3LYP/6-31G //TD-HF/6-31G level.

${ }^{g}$ Fluorescence quantum yield determined relative to fluorescein in $0.1 \mathrm{~N} \mathrm{NaOH}$.

${ }^{h}$ Experimental fluorescence lifetime determined using time-correlated single-photon counting (TCSPC).

${ }^{i}$ Radiative lifetime derived from fluorescence quantum yield and lifetime values (experimental values).

${ }^{l}$ Radiative lifetime derived from quantum-chemical calculations using Eq. (4) (calculated at TD-B3LYP/6-31G //TD-HF/6-31G level).

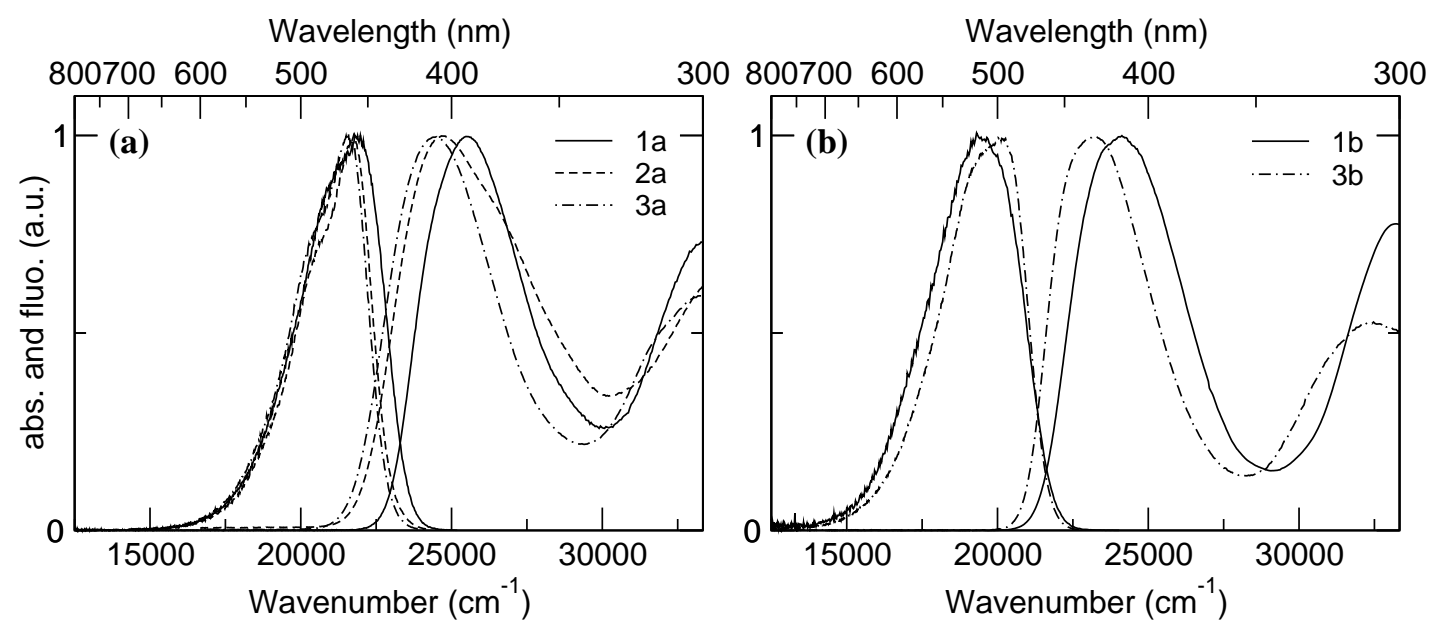

Figure 2: Normalized absorption and fluorescence spectra of (a) 1a-3a in toluene; (b) 1b, 2b in toluene. 


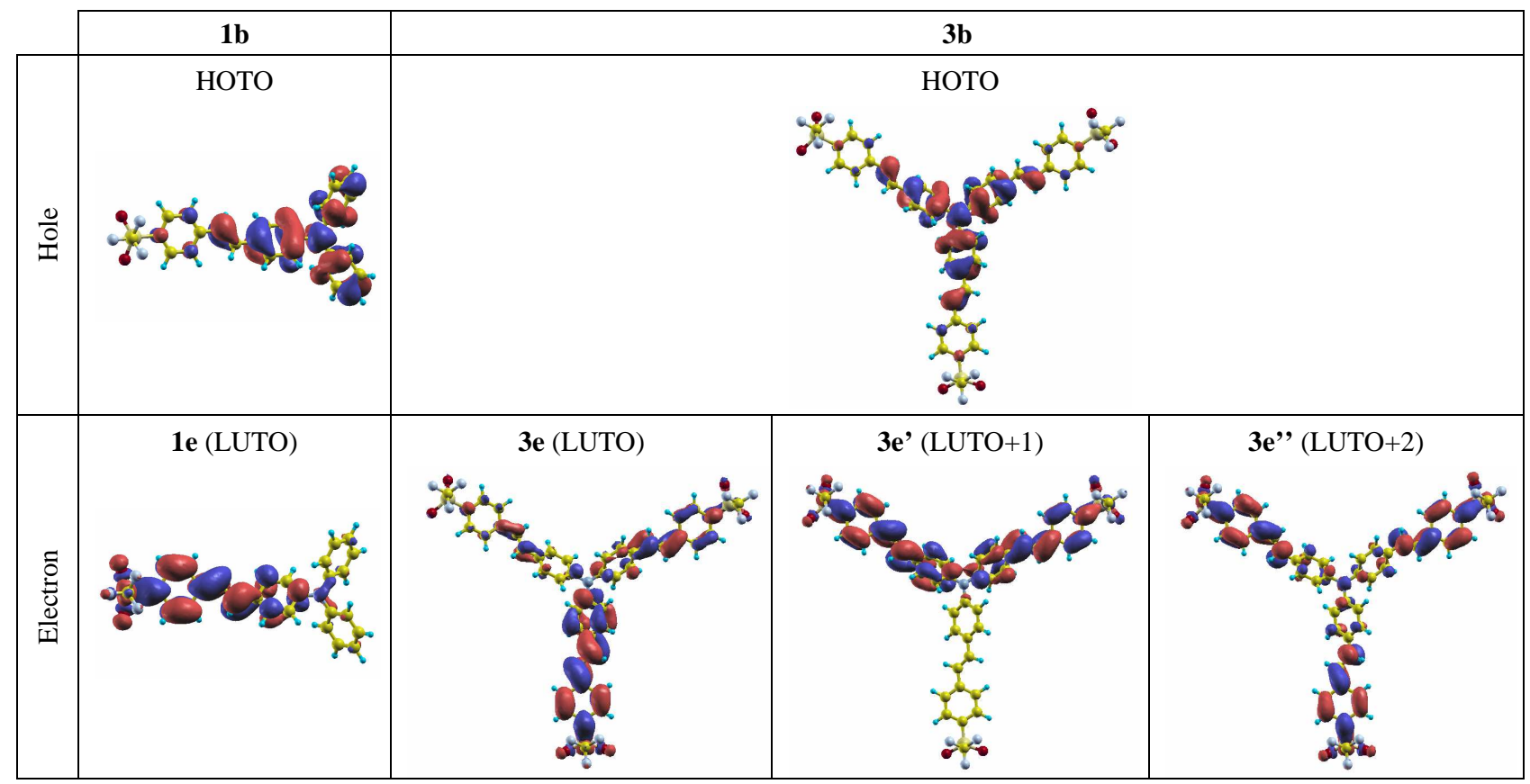

Figure 3: Natural transition orbitals for chromophore $\mathbf{1 b}$ and $\mathbf{3 b}$ relevant to absorption (optimized ground state geometry).

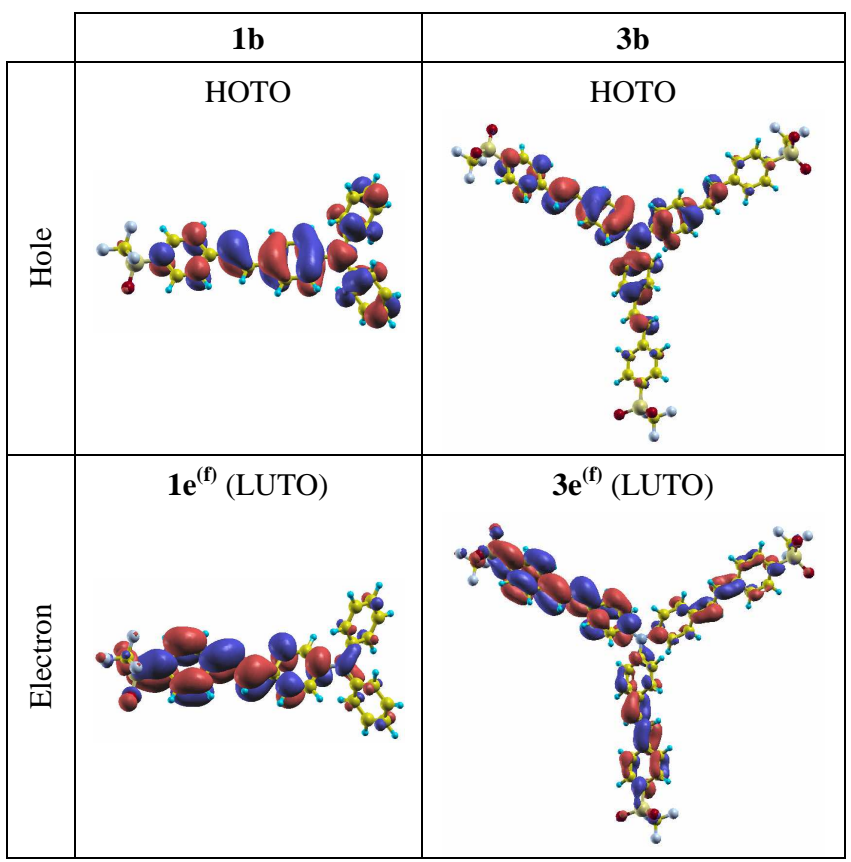

Figure 4: Natural transition orbitals for chromophore $\mathbf{1 b}$ and $\mathbf{3 b}$ relevant to emission (optimized excited state geometry). 
All chromophores investigated in the present work show a common feature: they exhibit large Stokes-shifts. This indicates that significant reorganization takes place after excitation prior to emission. Such behavior can be related to the electronic redistribution occurring upon excitation. Calculations reveal that pronounced intramolecular charge transfer occurs within the chromophores upon excitation. Figure 3 reveals that the HOTO $\rightarrow$ LUTO transition corresponds to a pronounced electron density shift from the triphenylamine moiety to the conjugated branche(s) in all chromophores. The directional intramolecular charge transfer leads to a significant dipolar character of the first excited state for chromophores 1a and 1b. Chromophore 2a combines dipolar and quadrupolar characteristics. For symmetry reasons, chromophores 3a and $\mathbf{3 b}$ undergo upon excitation a two-dimensional octupolar intramolecular charge transfer from the trigonal central core toward the branches. In all molecules a reversal of the bond length alternation in the conjugated branches is observed in relation with the charge-transfer phenomenon. As a consequence of the photoinduced charge transfer, nuclear reorganization takes place and the electronic density distribution itself readjusts in turn. Thus, the electronic density distribution relevant to the relaxed excited state (i.e. to the fluorescence process) is markedly different with respect to the absorption process, as it can be clearly seen in Figure 4.

\subsection{Solvatochromism}

All investigated chromophores show a marked positive emission solvatochromism: increasing solvent polarity leads to a pronounced bathochromic shift of the fluorescence band (Figure 5). Solvent polarity allows tuning of the photoluminescence in a significant way, varying typically from blue in toluene to green-yellow in acetonitrile for chromophores 1a-3a and from green to red for chromophores $\mathbf{1 b}$ and $\mathbf{3 b}$ (Table 1). In contrast, no noticeable shift is observed for the absorption bands (Figure 5). Accordingly, the Stokes-shifts significantly increase with increasing solvent polarity. Such behavior is consistent with a stabilization of highly polar emitting excited-states by polar solvents. In addition, the solvatochromic behavior of all chromophores follows the Lippert-Mataga relationship. ${ }^{75,76}$ Even more interestingly, the homologue derivatives of different dimensionality exhibit similar behavior and give rise to similar slopes of the Lippert-Mataga lines: this suggests that the emission stems from a dipolar state, i.e. from one of the dipolar branches, even in two- and three-branched chromophores. This corresponds to a localization of the relaxed excited state on a single branch. If the cavity radius is fixed as half the estimated distance between the donor and acceptor moieties on the branch (i.e. $\sim 5 \AA$ ), a value of $\mu_{e e}^{(f)}-\mu_{g g} \sim 13 \mathrm{D}$ is obtained for $\mathbf{1 a}$ and $\mathbf{1 b}$, which is in reasonable agreement with values obtained by theoretical calculations (Table 2). Even by using a more refined ellipsoidal cavity model (which might be more appropriate for such elongated molecules) including shape and dipole position correction factors ${ }^{77}$ and taking into account the total length of the dipolar molecule, we derive a change of dipole moment of about $14 \mathrm{D}$. These large values explain the marked sensitivity of the emission bands to solvent polarity.

Table 2: Theoretical results for the investigated chromophores, obtained at the TD-B3LYP/6-31G//HF/6-31G level. Superscript ${ }^{(\mathrm{f})}$ denotes the lowest excited state optimal geometry corresponding to fluorescence. Dipole moments are given only as contributions on the $x y$ plane (contributions along the $z$ axis are only relevant to local dipole moments due to terminal groups). Beyond the modulus of each dipole moment, the main polarization direction is indicated in parentheses.

\begin{tabular}{|c|c|c|c|c|c|c|c|c|c|c|c|c|c|}
\hline \multirow{2}{*}{$\frac{\text { Compound }}{\text { State }}$} & \multicolumn{2}{|c|}{$1 \mathrm{a}$} & \multicolumn{3}{|c|}{$2 a$} & \multicolumn{3}{|c|}{ 3a } & \multicolumn{2}{|c|}{$1 \mathrm{~b}$} & \multicolumn{3}{|c|}{$3 b$} \\
\hline & $1 \mathrm{e}$ & $1 e^{(f)}$ & $2 \mathrm{e}$ & $2 e^{(f)}$ & $2 \mathrm{e}^{\prime}$ & $3 e / 3 e^{\prime}$ & $3 e^{(f)}$ & $3 e^{\prime \prime}$ & $1 \mathrm{e}$ & $1 e^{(f)}$ & $3 \mathrm{e} / 3 \mathrm{e}^{\prime}$ & $3 \mathrm{e}^{(\mathrm{f})}$ & $3 e^{\prime \prime}$ \\
\hline$\Omega_{g e}^{a}(\mathrm{eV})$ & 3.04 & 2.73 & 2.89 & 2.58 & 3.17 & 2.90 & 2.55 & 3.30 & 2.84 & 2.61 & 2.75 & 2.44 & 3.10 \\
\hline$\mu_{g e}^{b}(\mathrm{D})$ & $8.5(x)$ & $11.7(x)$ & $10.4(x)$ & $12.9(x)$ & $4.7(y)$ & $9.5(x y)$ & $12.8(x)$ & 0 & $8.7(x)$ & $12.1(x)$ & $9.6(x y)$ & $13.0(x)$ & 0 \\
\hline$\mu_{g g}{ }^{c}(\mathrm{D})$ & $8.1(x)$ & $10.4(x)$ & $7.3(y)$ & $8.0(y)$ & $7.3(y)$ & 0 & $1.9(x)$ & 0 & $10.7(x)$ & $13.3(x)$ & 0 & $3.0(x)$ & 0 \\
\hline$\mu_{e e}{ }^{d}(\mathrm{D})$ & $26.9(x)$ & $19.2(x)$ & $14.8(y)$ & $13.1(y)$ & $14.8(y)$ & $13.7(x y)$ & $8.9(x)$ & 0 & $31.5(x)$ & $23.4(x)$ & $13.5(x y)$ & $6.3(x)$ & 0 \\
\hline
\end{tabular}

\footnotetext{
${ }^{a}$ Transition frequency; ${ }^{b}$ Transition dipole moment; ${ }^{c}$ Ground state dipole moment; ${ }^{d}$ Excited state dipole moment.
} 

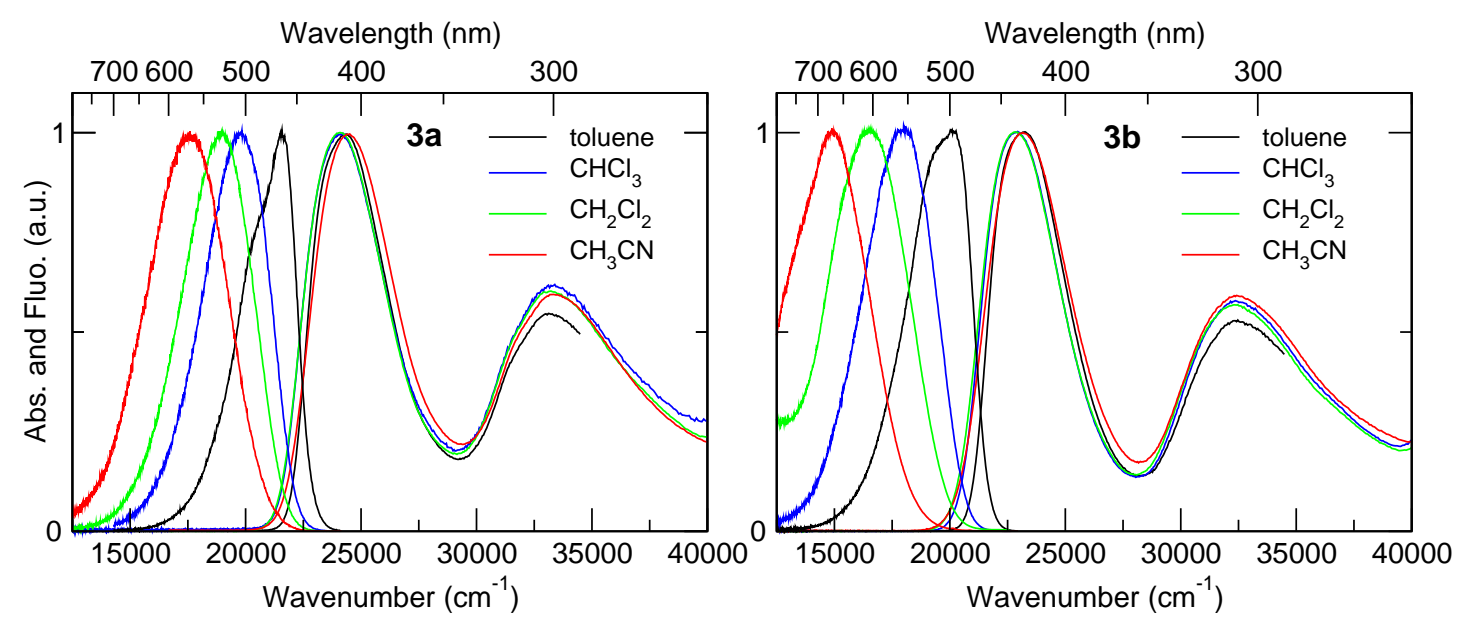

Figure 5: Solvatochromic behavior of chromophore 3a (left panel) and chromophore 3b (right panel).

\subsection{Excited state localization}

Transition orbitals representing the emitting states clearly show a localization of the excitation on one branch, compared to the respective absorbing states (Figure 4). The very similar nature of the emitting excited states for all the chromophores is also confirmed by the very similar fluorescence frequencies and by the trend of the Stokes shift. The reported calculations demonstrate that localization of the excitation is mainly due to molecular vibrations. This trend has a sounding counterpart in the Frenkel exciton model, where it is well known that vibrational relaxation introduces diagonal disorder, which leads to localization of the excitation itself. ${ }^{78}$ Solvation interaction can play an important role too, but in our case the non-dipolar nature of the chosen solvent (toluene) rules out a major effect due to the solvent. Practically calculations for the excited state predict an almost complete localization of the excitation as induced by nuclear relaxation only. Thus both theory and experiment consistently support localization of the emitting state on a single branch. This is a general feature of the class of systems studied here. Actually, this phenomenon has also been reported for other octupolar trigonal derivatives, as proven by analogous photophysical studies ${ }^{79,80}$ and time-resolved fluorescence anisotropy measurements. ${ }^{81-83}$ Excitation localization to a single monomer upon vibrational relaxation has also been predicted by recent theoretical investigations ${ }^{65,73}$ in other coupled aggregates composed by conjugated molecules. All these observations suggest that the phenomenon of localization of excitation is a quite common feature in interacting multichromophoric systems, where photoexcited individual branches undergo a significant vibrational relaxation and, in particular, in systems where excited states are characterized by (partial) charge-transfer character.

\subsection{Two-photon absorption}

TPA spectra of the investigated chromophores are shown in Figure 6(a), and data are summarized in Table 3. These spectra exhibit a first maximum close to twice the one-photon maximum absorption wavelength, indicating that the lowest energy excited-state is both one-photon and two-photon allowed. The first TPA maxima of the two- and threebranched chromophores are red-shifted with respect to that of the dipolar chromophores, as a result of the red-shift of the one-photon absorption band originating from the interaction between the branches. The corresponding TPA cross-section peak values increase with increasing number of branches. But for consistently comparing the responses of the components of the series, some normalization criterion must be set. A first normalization procedure is based on the molecular weight, as to obtain a relevant figure of merit for applications such as optical limitations. Examination of TPA values normalized following this criterion (i.e. $\sigma_{2} / \mathrm{MW}$ where $\mathrm{MW}$ is the molecular weight) at the first local maxima gives preliminary clues to the branching effect: we observe that branched chromophores show larger normalized TPA than the one-dimensional chromophores (Table 3). This enhancement is similar for the two- and three-branched derivatives 2a and 3a (about 1.4-1.6), and it is significantly larger for the three-branched derivative 3b (about 2.1). Furthermore, branched chromophores show larger normalized TPA $\left(\sigma_{2} / \mathrm{MW}\right)$ than the dipolar chromophores in the whole spectral range, indicating that the branching approach is a valid strategy for obtaining materials with increased TPA figure of merit. Normalized peak-TPA values lead to very high amplification factors for octupolar derivatives: $\geq 5$ for $\mathbf{3 a}$ and $\sim 7$ for $\mathbf{3 b}$. 

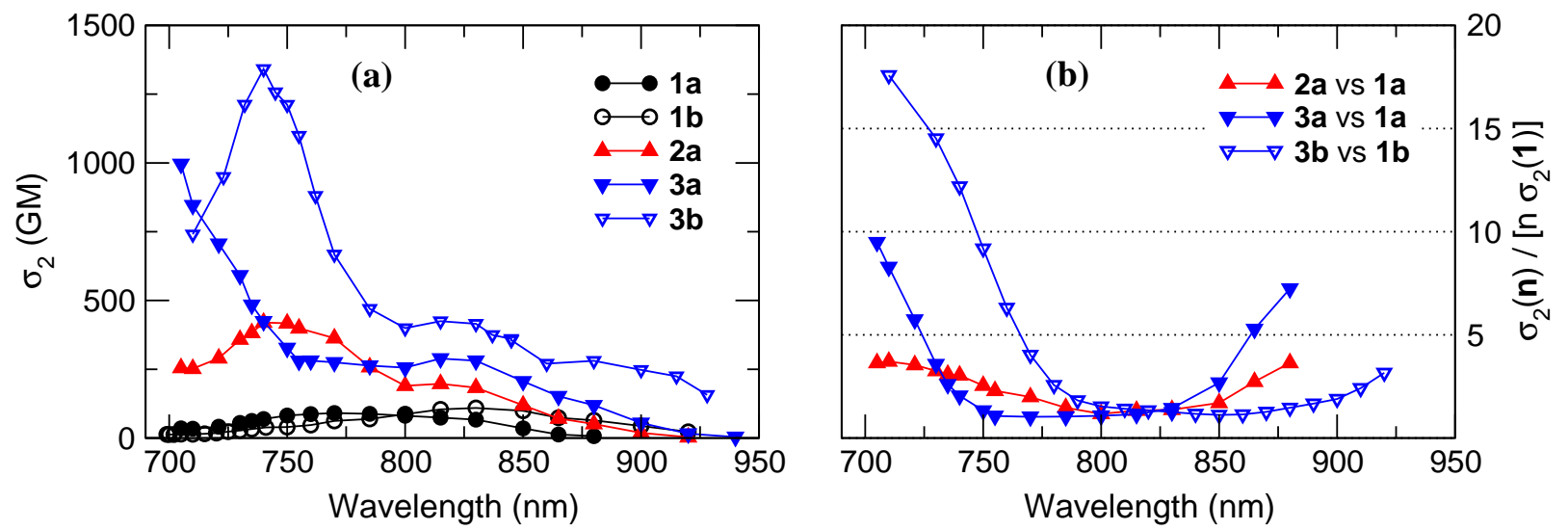

Figure 6: (a) TPA cross section of the investigated chromophores in toluene. (b) Wavelength dependence of the TPA enhancement due to the branching effect. Filled symbols: $\mathrm{SO}_{2} \mathrm{Oct}$ series; Open symbols: $\mathrm{SO}_{2} \mathrm{CF}_{3}$ series.

Table 3: Two-photon absorption data of the investigated chromophores (in toluene).

\begin{tabular}{|c|c|c|c|c|c|c|c|}
\hline \multirow[b]{2}{*}{ Compound } & \multirow[b]{2}{*}{$2 \lambda_{\mathrm{abs}}(\mathrm{nm})$} & \multirow[b]{2}{*}{$\lambda_{\mathrm{TPA}}^{\max 1}(\mathrm{~nm})$} & \multirow[b]{2}{*}{$\lambda_{\mathrm{TPA}}^{\max 2}(\mathrm{~nm})$} & \multicolumn{2}{|c|}{$\sigma_{2}^{a}(\mathrm{GM})$} & \multicolumn{2}{|c|}{$\sigma_{2} / \mathrm{MW}\left(\mathrm{GM} \mathrm{g}^{-1} \mathrm{~mol}\right)$} \\
\hline & & & & at $\lambda_{\mathrm{TPA}}^{\max 1}$ & at $\lambda_{\mathrm{TPA}}^{\max 2}$ & at $\lambda_{\mathrm{TPA}}^{\max 1}$ & at $\lambda_{\mathrm{TPA}}^{\max 2}$ \\
\hline $1 \mathrm{a}$ & 784 & 770 & - & 90 & - & 0.17 & - \\
\hline $2 a$ & 818 & 815 & 740 & 195 & 420 & 0.24 & 0.52 \\
\hline $3 \mathbf{a}$ & 820 & 815 & $\leq 705$ & 290 & $>995$ & 0.27 & $>0.92$ \\
\hline $1 b$ & 830 & 830 & - & 110 & - & 0.21 & - \\
\hline $3 \mathbf{b}$ & 860 & 820 & 740 & 430 & 1340 & 0.45 & 1.41 \\
\hline
\end{tabular}

${ }^{a}$ TPA cross-sections; $1 \mathrm{GM}=10^{-50} \mathrm{~cm}^{4} \mathrm{~s}_{\text {photon }}{ }^{-1}$.

Another normalization criterion can be chosen by simply rescaling the TPA response for the number of branches. This analysis yields better information on the intrinsic charge-symmetry and branching effect, allowing to distinguish additive behavior from cooperative effects. Figure 6(b) shows the enhancement factor for branched chromophores, calculated as the ratio between the TPA cross section of the n-branched structure and n-times the TPA cross section of the corresponding dipole. The TPA responses of branched compounds always show an enhancement with respect to their dipolar analogue, and this enhancement is wavelength dependent. In particular, it is weak near the first TPA maxima but significantly increases at lower and higher energies. This behavior can be qualitatively interpreted through the exciton model. Indeed, interactions between branches lead to an energy separation between the (otherwise degenerate) excited states, so that final states are split toward higher and lower energy with respect to the monomeric analogue. The consequence is a TPA activity of branched compounds in spectral regions respectively blue- and red-shifted with respect to the monomer. In other words, a TPA enhancement is obtained in regions where the dipolar reference system is also two-photon active, and a true TPA activation is attained in regions (especially towards the blue side) where the monomeric model is (almost) two-photon transparent. While these effects are clearly recognizable in Figure 7 for all branched systems, the most striking example is given by compound $\mathbf{3 b}$, for which the second (high-energy side) TPA maximum is reached in the investigated spectral window: an enhancement of $\sim 20$ is obtained near $700 \mathrm{~nm}$.

In Figure 7, experimental TPA spectra (circles) are compared with calculated results. For a better comparison, calculated spectra have been obtained by introducing a local field factor (spherical cavity, see Eq. (2)), which accounts for toluene $(n=1.494)$ as solvent. Given the uncertainty of the TPA cross-section line-width, we did not apply more sophisticated cavity/solvent models. However, to emphasize the expected trends, we conducted TD-B3LYP calculations of the excited structure and TPA profiles using the polarizable continuum model implemented in Gaussian $98 .{ }^{51}$ For all the investigated molecules, these calculations show a consistent solvatochromic red-shift of TPA excitation frequencies by $\sim 30-60$ meV 
and an increase of the corresponding cross-sections by $\sim 10 \%$ (most notably in the dipolar compound). The global agreement between experimental and calculated spectra is good: a part from deviations due to global line-width and spectral shift $(\sim 0.07 \mathrm{eV})$, computational results for chromophores $\mathbf{1 a}, \mathbf{1 b}$ and $\mathbf{2 a}$ are very satisfactory. The comparison formally worsens for the higher energy band of octupolar chromophores, which experimentally is displaced towards higher energy. Calculations predict a strong enhancement due to the two degenerate excited states, with a maximum at about $750 \mathrm{~nm}$ for $\mathbf{3 a}$ and $800 \mathrm{~nm}$ for $\mathbf{3 b}$, while the experimental TPA cross-section still increases between 730 and 705 $\mathrm{nm}$ for $\mathbf{3 a}$ and has its maximum at $740 \mathrm{~nm}$ for $\mathbf{3 b}$. TPA spectrum of $\mathbf{3 b}$ allows to conclude that the splitting of excited states does not respect the exciton model prediction. Calculations also reproduce this trend, even if predicted deviations are somewhat smaller than experimentally observed. In general for all the studied compounds, also deviations in the lowenergy side of the spectrum are found with respect to experimental results: the enhancement factor calculated for branched systems is underestimated by calculations in this region. A possible explanation for discrepancies is the neglect of molecular vibrations and inhomogeneous broadening effects in calculations, which can have important consequences on the shape (and, to a minor extent, position) of optical bands.

The large, amplified TPA response shown by branched chromophores is related to the interaction between the branched dipolar units. We stress that this enhancement is underestimated by the Frenkel exciton approach, ${ }^{45}$ while it is better reproduced by quantum-chemical calculations using supramolecular approach. Thus correct prediction of the enhancement in the TPA response of branched chromophores requires accounting for the presence of coherent interactions between branches (beyond dipolar model) ${ }^{81}$ and higher lying excited states. ${ }^{26}$ Moreover, we observe that the three-branched compound 3a leads to a larger cooperative effect than the analogous two-branched system 2a. This suggests that further TPA enhancement could be achieved in n-branched systems $(n>3)$ built from a core allowing significant coupling between the branches and from branches ensuring pronounced intramolecular charge transfer between the center and the periphery upon excitation.

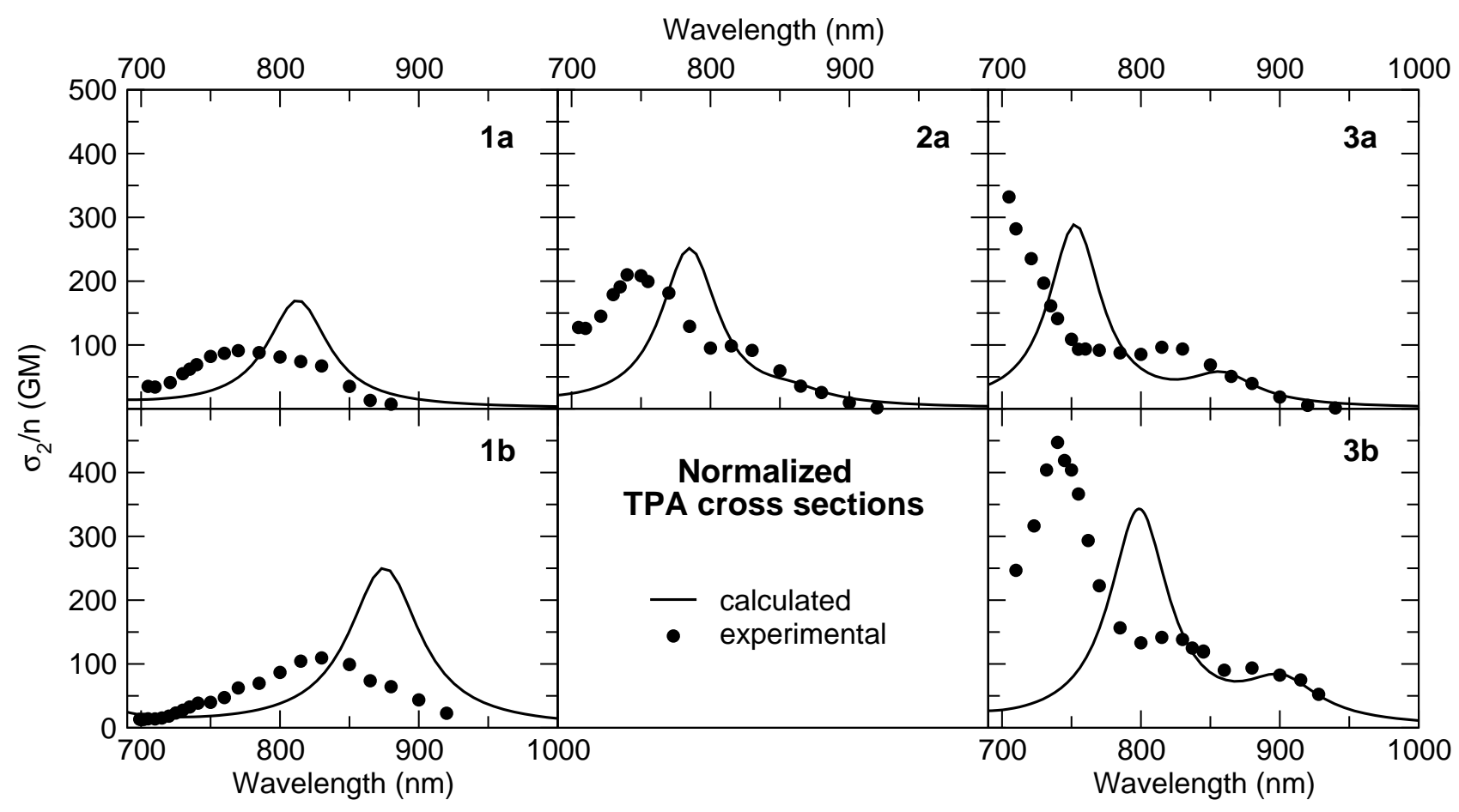

Figure 7: TPA cross sections normalized for the number of branches. Experimental (dots) vs. calculated (full lines) results. 


\section{CONCLUSIONS}

The branching effect of dipolar units on linear and nonlinear optical properties of multipolar chromophores has been investigated through a combined theoretical and experimental approach. Upon excitation all chromophores show pronounced intramolecular charge transfer from the donating central moiety to the electron-withdrawing peripheral groups, so that the basic physics can be described in terms of delocalized Frenkel exciton states. On the contrary, emission stems from a strongly dipolar state, well localized over a single branch. High-level quantum chemical calculations demonstrate that this localization is a consequence of nuclear relaxation and is not linked to particular environmental conditions, suggesting that this phenomenon is quite general. This particular feature allows maintaining high fluorescence quantum yield and long fluorescence lifetime for multibranched compounds. The one- and two-photon absorption properties of the branched structures indicate that the dipolar branches significantly interact. This coupling not only induces shifts of the one- and two-photon absorption bands, but also results in strong TPA enhancement in the whole relevant spectral region. The coupling of dipolar chromophores within the (two- and three-) branched structures is in fact responsible for a mixing of single-branch excited states, with important consequences on the nature of the excited states themselves. Not only an amplification is obtained in the low-energy region of the TPA spectrum, but also the appearance of a blue-shifted intense new band is observed, corresponding to a true TPA activation in spectral regions where the dipolar analogue is almost two-photon transparent.

Thus the appropriate tuning of the number of branches, the coupling between them and the modulation of the intramolecular charge transfer from the core to the periphery may constitute a substantial way for obtaining cooperative amplification of TPA efficiency in desired spectral regions, making the branching strategy not only of fundamental interest, but also appealing for various applications.

\section{ACKNOWLEDGMENTS}

We wish to thank Dr. Bharath K. G. Bhatthula for contribution to the synthesis, and Prof. J. Mertz and T. Pons for contribution to TPA measurements. MBD and MHVW are grateful to Rennes Métropole ("Allocation d'Installation Scientifique"). MBD also acknowledges partial financial support from CNRS (NOI grant). Financial support from Région Bretagne ("Renouvellement des compétences" Program) is acknowledged too. LP received a fellowship from the French Ministère de l'Education Nationale, de l'Enseignement Supérieur et de la Recherche. FT acknowledges support by a Marie Curie Intra-European Fellowship within the 6th European Community Framework Programme. Part of calculations was supported by the "Centre Informatique National de l'Enseignement Supérieur" (CINES-France). The research at LANL is supported by Center for Nonlinear Studies (CNLS) and the LDRD program of the US Department of Energy: this support is gratefully acknowledged.

\section{REFERENCES}

1. G. S. He, L. Yuan, N. Cheng, J. D. Bhawalkar, P. N. Prasad, L. L. Brott, S. J. Clarson, B. A. Reinhardt, J. Opt. Soc. Am. B 14, 1079 (1997).

2. B. A. Reinhardt, L. L. Brott, S. J. Clarson, A. G. Dillard, J. C. Bhatt, R. Kannan, L. Yuan, G. S. He, P. N. Prasad, Chem. Mater. 10, 1863 (1998).

3. K. D. Belfield, D. J. Hagan, E. W. Van Stryland, K. J. Schafer, R. A. Negres, Org. Lett. 1, 1575 (1999).

4. O.-K. Kim, K.-S. Lee, H. Y. Woo, K.-S. Kim, G. S. He, S. H. Guang, J. Swiatkiewicz, P. N. Prasad, Chem. Mater. 12, 284 (2000).

5. A. Abbotto, L. Beverina, R. Bozio, S. Bradamante, C. Ferrante, G. A. Pagani, R. Signorini, Adv. Mater. 12, 1963 (2000).

6. $\quad$ B. Strehmel, A. M. Sarker, H. Detert, ChemPhysChem 4, 249 (2003).

7. L. Antonov, K. Kamada, K. Ohta, F. S. Kamounah, Phys. Chem. Chem. Phys. 5, 1193 (2003).

8. J. Kawamata, M. Akiba, T. Tani, A. Harada, Y. Inagaki, Chem. Lett. 33, 448 (2004).

9. G. S. He, G. C. Xu, P. N. Prasad, B. A. Reinhardt, J. C. Bhatt, R. McKellar, A. G. Dillard, Opt. Lett. 20, 435 (1995).

10. J. E. Ehrlich, X. L. Wu, I.-Y. S. Lee, Z.-Y. Hu, H. Röckel, S. R. Marder, J. W. Perry, Opt. Lett. 22, 1843 (1997). 
11. M. Albota, D. Beljonne, J.-L. Brédas, J. E. Ehrlich, J.-Y. Fu, A. A. Heikal, S. E. Hess, T. Kogej, M. D. Levin, S. R. Marder, D. McCord-Maughon, J. W. Perry, H. Röckel, M. Rumi, G. Subramaniam, W. W. Webb, X.-L. Wu, C. Xu, Science 281, 1653 (1998).

12. L. Ventelon, M. Blanchard-Desce, L. Moreaux, J. Mertz, Chem. Commun., 2055 (1999).

13.

14.

15 .

16.

17.

18.

19.

20 .

21.

22.

23.

24.

25.

26.

L. Ventelon, S. Charier, L. Moreaux, J. Mertz, M. Blanchard-Desce, Angew. Chem., Int. Ed. 40, 2098 (2001).

P. K. Frederiksen, M. Jørgensen, P. R. Ogilby, J. Am. Chem. Soc. 123, 1215 (2001).

L. Ventelon, L. Moreaux, J. Mertz, M. Blanchard-Desce, Synth. Met. 127, 17 (2002).

O. Mongin, L. Porrès, L. Moreaux, J. Mertz, M. Blanchard-Desce, Org. Lett. 4, 719 (2002).

S. J. K. Pond, M. Rumi, M. D. Levin, T. C. Parker, D. Beljonne, M. W. Day, J.-L. Brédas, S. R. Marder, J. W. Perry, J. Phys. Chem. A 106, 11470 (2002).

A. Abbotto, L. Beverina, R. Bozio, A. Facchetti, C. Ferrante, G. A. Pagani, D. Pedron, R. Signorini, Org. Lett. 4, 1495 (2002).

O. K. Kim, K. S. Lee, Z. Huang, W. B. Heuer, C. S. Paik-Sung, Opt. Mater. 21, 559 (2003).

W. J. Yang, D. Y. Kim, M.-Y. Jeong, H. M. Kim, S.-J. Jeon, B. R. Cho, Chem. Commun., 2618 (2003).

Y. Iwase, K. Kamada, K. Ohta, K. Kondo, J. Mater. Chem. 13, 1575 (2003).

M. P. Joshi, J. Swiatkiewicz, F. Xu, P. N. Prasad, B. A. Reinhardt, R. Kannan, Opt. Lett. 23, 1742 (1998).

S.-J. Chung, K.-S. Kim, T.-C. Lin, G. S. He, J. Swiatkiewicz, P. N. Prasad, J. Phys. Chem. B 103, 10741 (1999). G. S. He, J. Swiatkiewicz, Y. Jiang, P. N. Prasad, B. A. Reinhardt, L.-S. Tan, R. Kannan, J. Phys. Chem. A 104, 4805 (2000).

B. R. Cho, K. H. Son, H. L. Sang, Y.-S. Song, Y.-K. Lee, S.-J. Jeon, J. H. Choi, H. Lee, M. Cho, J. Am. Chem. Soc. 123, 10039 (2001).

D. Beljonne, W. Wenseleers, E. Zojer, Z. Shuai, H. Vogel, S. J. K. Pond, J. W. Perry, S. R. Marder, J.-L. Brédas, Adv. Funct. Mater. 12, 631 (2002).

O. Mongin, J. Brunel, L. Porrès, M. Blanchard-Desce, Tetrahedron Lett. 44, 2813 (2003).

O. Mongin, L. Porrès, C. Katan, T. Pons, J. Mertz, M. Blanchard-Desce, Tetrahedron Lett. 44, 8121 (2003).

L. Porrès, O. Mongin, C. Katan, M. Charlot, T. Pons, J. Mertz, M. Blanchard-Desce, Org. Lett. 6, 47 (2004).

H. J. Lee, J. Sohn, J. Hwang, S. Y. Park, H. Choi, M. Cha, Chem. Mater. 16, 456 (2004).

W. J. Yang, D. Y. Kim, C. H. Kim, M.-Y. Jeong, S. K. Lee, S.-J. Jeon, B. R. Cho, Org. Lett. 6, 1389 (2004).

F. Meng, B. Li, S. Qian, K. Chen, H. Tian, Chem. Lett. 33, 470 (2004).

C. W. Spangler, E. H. Elandaloussi, M. K. Casstevens, D. N. Kumar, J. F. Weibel, R. Burzynski, Proc. SPIEInt. Soc. Opt. Eng. 3798, 117 (1999).

A. M. McDonagh, M. G. Humphrey, M. Samoc, B. Luther-Davies, Organometallics 18, 5195 (1999).

A. Adronov, J. M. J. Fréchet, G. S. He, K.-S. Kim, S.-J. Chung, J. Swiatkiewicz, P. N. Prasad, Chem. Mater. 12, 2838 (2000).

S.-J. Chung, T.-C. Lin, K.-S. Kim, G. S. He, J. Swiatkiewicz, P. N. Prasad, G. A. Baker, F. V. Bright, Chem. Mater. 13, 4071 (2001).

M. Drobizhev, A. Karotki, A. Rebane, C. W. Spangler, Opt. Lett. 26, 1081 (2001).

M. Drobizhev, A. Karotki, M. Kruk, N. Z. Mamardashvili, A. Rebane, Chem. Phys. Lett. 361, 504 (2002).

A. Abbotto, L. Beverina, R. Bozio, A. Facchetti, C. Ferrante, G. A. Pagani, D. Pedron, R. Signorini, Chem. Commun., 2144 (2003).

M. Drobizhev, A. Karotki, Y. Dzenis, A. Rebane, Z. Suo, C. W. Spangler, J. Phys. Chem. B 107, 7540 (2003).

J. Yoo, S. K. Yang, M.-Y. Jeong, H. C. Ahn, S.-J. Jeon, B. R. Cho, Org. Lett. 5, 645 (2003).

S. Liu, K. S. Lin, V. M. Churikov, Y. Z. Su, J. T. s. Lin, T.-H. Huang, C. C. Hsu, Chem. Phys. Lett. 390,433 (2004).

M. Drobizhev, A. Rebane, Z. Suo, C. W. Spangler, J. Lumin. 111, 291 (2005).

T. G. Goodson, Acc. Chem. Res. 38, 99 (2004).

C. Katan, F. Terenziani, O. Mongin, M. H. V. Werts, L. Porrès, T. Pons, J. Mertz, S. Tretiak, M. BlanchardDesce, J. Phys. Chem. A 109, 3024 (2005).

T. Mallegol, S. Gmouh, M. Ait Amer Meziane, M. Blanchard-Desce, O. Mongin, Synthesis 11, 1771 (2005).

C. Le Droumaguet, O. Mongin, M. H. V. Werts, M. Blanchard-Desce, Chem. Commun. 22, 2802 (2005).

J. N. Demas, G. A. Crosby, J. Phys. Chem. 75, 991 (1971).

C. Xu, W. W. Webb, J. Opt. Soc. Am. B 13, 481 (1996).

M. A. Albota, C. Xu, W. W. Webb, Appl. Opt. 37, 7352 (1998). 
51. Gaussian 98 (Revision A.11), M. J. Frisch, G. W. Trucks, H. B. Schlegel, G. E. Scuseria, M. A. Robb, J. R. Cheeseman, V. G. Zakrzewski, J. A. Montgomery, Jr., R. E. Stratmann, J. C. Burant, S. Dapprich, J. M. Millam, A. D. Daniels, K. N. Kudin, M. C. Strain, O. Farkas, J. Tomasi, V. Barone, M. Cossi, R. Cammi, B. Mennucci, C. Pomelli, C. Adamo, S. Clifford, J. Ochterski, G. A. Petersson, P. Y. Ayala, Q. Cui, K. Morokuma, P. Salvador, J. J. Dannenberg, D. K. Malick, A. D. Rabuck, K. Raghavachari, J. B. Foresman, J. Cioslowski, J. V. Ortiz, A. G. Baboul, B. B. Stefanov, G. Liu, A. Liashenko, P. Piskorz, I. Komaromi, R. Gomperts, R. L. Martin, D. J. Fox, T. Keith, M. A. Al-Laham, C. Y. Peng, A. Nanayakkara, M. Challacombe, P. M. W. Gill, B. Johnson, W. Chen, M. W. Wong, J. L. Andres, C. Gonzalez, M. Head-Gordon, E. S. Replogle, and J. A. Pople, Gaussian, Inc., Pittsburgh PA, 2001.

52. D. J. Tozer, J. Chem. Phys. 119, 12697 (2003).

53. A. Masunov, S. Tretiak, J. Phys. Chem. B 108, 899 (2004).

54. F. Furche, R. Ahlrichs, J. Chem. Phys. 117, 7433 (2002).

55. M. E. Casida, C. Jamorski, K. C. Casida, D. R. Salahub, J. Chem. Phys. 108, 4439 (1998).

56. G. Onida, L. Reining, A. Rubio, Rev. Mod. Phys. 74, 601 (2002).

57. S. Tretiak, V. Chernyak, J. Chem. Phys. 119, 8809 (2003).

58. G. P. Bartholomew, M. Rumi, S. J. Pond, J. W. Perry, S. Tretiak, G. C. Bazan, J. Am. Chem. Soc. 126, 11529 (2004).

59. N. Kobko, A. Masunov, S. Tretiak, Chem. Phys. Lett. 392, 444 (2004).

60. A. F. Garito, J. R. Heflin, K. Y. Wong, O. Zamani-Khamiri, in Organic Materials for Non-linear Optics R. A. Hann, D. Bloor, Eds. (Royal Society of Chemistry, London, 1989) pp. 16.

61. R. Ahlrichs, M. Bär, M. Häser, H. Horn, C. Kölmel, Chem. Phys. Lett. 162, 165 (1989).

62. P. Meystre, M. Sargent III, Elements of Quantum Optics (Springer-Verlag, Berlin Heidelberg New York, ed. Second Edition, 1991).

63. M. E. Crenshaw, C. M. Bowden, Phys. Rev. Lett. 85, 1851 (2000).

64. R. L. Martin, J. Chem. Phys. 118, 4775 (2003).

65. I. Franco, S. Tretiak, J. Am. Chem. Soc. 126, 12130 (2004).

66. MOLEKEL 4.0, P. Flükiger, H. P. Lüthi, S. Portmann, J. Weber, Swiss Center for Scientific Computing, Manno (Switzerland), 2000.

67. A. Kokalj, J. Mol. Graphics Mod. 17, 176 (1999).

68. A. S. Davidov, Theory of molecular excitons (Plenum Press, New York, 1971).

69. E. A. Silinsh, V. Capek, Organic Molecular Crystals: Interaction, Localization, and Transport Phenomena (AIP Press, New York, 1994).

70. S. Tretiak, V. Chernyak, S. Mukamel, J. Phys. Chem. B 102, 3310 (1998).

71. A. N. Sobolev, V. K. Belsky, I. P. Romm, N. Y. Chernikova, E. N. Guryanova, Acta Crystallogr., Sect. C: Cryst. Struct. Commun. C41, 967 (1985).

72. J.-L. Brédas, J. Cornil, D. Beljonne, D. A. Dos Santos, Z. Shuai, Acc. Chem. Res. 32, 267 (1999).

73. S. Tretiak, A. Saxena, R. L. Martin, A. R. Bishop, Phys. Rev. Lett. 89, 097402 (2002).

74. S. J. Strickler, R. A. Berg, J. Chem. Phys. 37, 814 (1962).

75. E. Lippert, Z. Naturforsch. A 10, 541 (1955).

76. N. Mataga, Y. Kaifu, M. Koizumi, Bull. Chem. Soc. Jpn. 28, 690 (1955).

77. $\quad$ P. Suppan, J. Photochem. Photobiol., A 50, 293 (1990).

78. H. Fidder, J. Knoester, D. A. Wiersma, J. Chem. Phys. 95, 7880 (1991).

79. W. Verbouwe, L. Viaene, M. Van der Auweraer, F. C. De Schryver, H. Masuhara, R. Pansu, J. Faure, J. Phys. Chem. A 101, 8157 (1997).

80. W. Verbouwe, M. Van der Auweraer, F. C. De Schryver, J. J. Piet, J. M. Warman, J. Am. Chem. Soc. 120, 1319 (1998).

81. S. A. Lahankar, R. West, O. Varnavski, X. Xie, T. Goodson III, J. Chem. Phys. 120, 337 (2004).

82. O. P. Varnavski, J. C. Ostrowski, L. Sukhomlinova, R. J. Twieg, G. Bazan, C., T. Goodson III, J. Am. Chem. Soc. 124, 1736 (2002).

83. Y. Wang, G. S. He, P. N. Prasad, T. Goodson III, J. Am. Chem. Soc. 127, 10128 (2005). 